\title{
Regulation of lysophosphatidic acid receptor-stimulated response by G-protein-coupled receptor kinase-2 and $\beta$-arrestin1 in FRTL-5 rat thyroid cells
}

\author{
L lacovelli, L Capobianco, G M D'Ancona, A Picascia \\ and A De Blasi
}

INM Neuromed, IRCCS, Località Camerelle, 86077 Pozzilli (IS), Italy

(Requests for offprints should be addressed to A De Blasi; Email: deblasi@neuromed.it)

\begin{abstract}
Lysophosphatidic acid (LPA) is a naturally occurring phospholipid that activates a variety of biological activities including cell proliferation. Three mammalian LPA receptor (LPAr) subtypes have been identified by molecular cloning, named $1 \mathrm{p}_{\mathrm{A} 1}, \mathrm{l}_{\mathrm{A} 2}$ and $\mathrm{lp}_{\mathrm{A} 3}$, that are coupled to heterotrimeric G-proteins for signal transduction. The LPAr are endogenously expressed in the rat thyroid cell line FRTL-5 and we used the FRTL-5 cells permanently transfected to obtain moderate overexpression of G-protein-coupled receptor kinase-2 (GRK2) or $\beta$-arrestin1 to study whether GRK2 and $\beta$-arrestin1 desensitise LPAr-mediated signalling and regulate LPAstimulated functional effects.

Using RT-PCR we documented that $l p_{\mathrm{A} 1}, \mathrm{p}_{\mathrm{A} 2}$ and $1 \mathrm{p}_{\mathrm{A} 3}$ receptors are all expressed in FRTL-5 cells. We then analysed the signal transduction of the LPAr in FRTL-5 cells. Exposure to LPA did not stimulate inositol phosphate formation nor cAMP accumulation but reduced forskolin-stimulated cAMP. LPA was also able to stimulate MAP kinase activation and this effect was abolished by pertussis toxin pretreatment. These results suggest that LPAr are mainly coupled to a pertussis toxin-sensitive G-protein in FRTL-5 cells.

In order to investigate whether GRKs and arrestins are involved in the regulation of LPAr-mediated signalling,
\end{abstract}

we used the FRTL-5 cell line permanently transfected to overexpress GRK2 (named L5GRK2 cells) or $\beta$-arrestin1 (L5ßarr1 cells). The ability of LPA to inhibit forskolinstimulated cAMP accumulation was blunted in L5GRK2 and more markedly in L5 $\beta$ arr 1 . The MAP kinase activation was also blunted in L5GRK2 and in L5 $\beta$ arr1B cells. Exposure to $20 \mu \mathrm{M} \mathrm{LPA}$ increased the phosphorylation of extracellular signal-regulated kinases ERK1/2 by 3-fold in L5pBJI cells (FRTL-5 cells transfected with the empty vector $\mathrm{pBJI}$ ) while it induced a modest increase in L5 $\beta$ arr1 and was ineffective in L5GRK2.

We measured $\left[{ }^{3} \mathrm{H}\right]$ thymidine uptake in L5 3 arr1B and in L5 GRK2 cells to test whether GRK2 and $\beta$-arrestin1 could have a role in the regulation of LPAr-mediated cell proliferation. The mitogenic response induced by $35 \mu \mathrm{M}$ LPA was substantially blunted in L5 $\beta$ arr1 $(-69 \pm 6 \%)$ and in L5GRK2 $(-69 \cdot 8 \pm 4 \cdot 5 \%)$ cells as compared with L5pBJI. Our findings document that the receptor-mediated responses elicited by LPA are regulated by GRK 2 and $\beta$-arrestin 1 in FRTL- 5 cells and indicate that this mechanism is potentially important for the control of the LPA-stimulated proliferative response.

Journal of Endocrinology (2002) 174, 103-110

\section{Introduction}

Lysophosphatidic acid (LPA) is a naturally occurring phospholipid that activates a variety of biological activities in higher eukaryotes, promoting cell proliferation, smooth muscle contraction, platelet aggregation, reversal of neuroblastoma differentiation and changes in cell morphology and adhesion. LPA activates specific cell surface receptors that are members of the G-protein-coupled receptor (GPCR) superfamily (Contos et al. 2000, Kraneburg \& Moolenar 2001). Three mammalian LPA receptor (LPAr) subtypes have been identified by molecular cloning, named $l p_{\mathrm{A} 1}, l p_{\mathrm{A} 2}$ and $l \mathrm{p}_{\mathrm{A} 3}$ (Contos et al. 2000), which can couple to different heterotrimeric G-proteins for signal transduction. Depending on the cell system, LPAr stimulation could regulate the activity of different effectors, such as stimulation of phospholipase $\mathrm{C}$ and phospholipase $\mathrm{A}_{2}$, activation of the MAP kinase cascade and inhibition of adenylyl cyclase.

It has been shown for several GPCRs that the process of signal transduction must be properly regulated in order to prevent overstimulation, achieve signal termination and render the receptor responsive to subsequent stimuli. Prolonged or repeated exposure of GPCRs to their 
agonists induces diminished cellular response to following agonist stimulation. This process, named homologous desensitisation, involves the activity of proteins belonging to two distinct families: the G-protein-coupled receptor kinases (GRKs) and arrestins (Miller \& Lefkowitz 2001, Pierce et al. 2001). The agonist-occupied receptor is phosphorylated by the GRK at serine/threonine residues, thus allowing the binding of arrestin and consequent uncoupling from the G-protein. The GRK family is composed of six cloned members named GRK1-6. GRK2 (previously known as $\beta$-adrenergic receptor kinase) is the prototype GRK. Molecular cloning has so far identified four arrestins. Two subtypes are selectively expressed in the retina, where they regulate phototransduction, while $\beta$-arrestin1 and 2 are expressed in many cell types. The two human splice variants of $\beta$-arrestin1 are named $\beta$-arrestin1A and B (Parruti et al. 1993).

Similar to many other GPCRs, agonist exposure induces the desensitisation of LPAr (Fischer et al. 1998, Kakizawa et al. 1998, Gueguen et al. 1999), but the mechanism involved in this process has not been elucidated. The present investigation was aimed at addressing this point. We used the rat thyroid cell line FRTL-5 permanently transfected to obtain moderate overexpression of GRK2 or $\beta$-arrestin1, which, as shown by our previous work, provides a useful tool to study the homologous desensitisation of GPCRs naturally expressed in FRTL-5 cells (Iacovelli et al. 1996, 1999). The LPAr is endogenously expressed in FRTL-5 cells and we document that in these cells GRK2 and $\beta$-arrestin1 desensitise LPAr-mediated signalling and regulate LPA-stimulated functional effects.

\section{Materials and Methods}

\section{Cell culture and transfection}

FRTL-5 cells are a continuous line of Fisher rat thyroid cells that maintain in vitro the proliferation and differentiation properties of the rat thyroid. FRTL-5 cells were cultured as previously described (Iacovelli et al. 1996). Briefly, FRTL-5 were maintained in Coon's modified F-12 medium supplemented with 5\% calf serum, $20 \mathrm{mM}$ glutamine and a mixture of six hormones (thyrotrophin (TSH), insulin, transferrin, somatostatin, cortisol and glycyl-L-hystytidyl-L-lysine acetate) and grown at $37^{\circ} \mathrm{C}$ in a humidified atmosphere of $5 \% \mathrm{CO}_{2}$.

FRTL-5 cells overexpressing GRK2 (named L5 GRK2) or $\beta$-arrestin1 (named L5 $\beta$ arr1) were derived from FRTL-5 cells stably transfected with GRK2 cDNA and $\beta$-arrestin1 (splicing 1B) cDNA. The transfection protocol and selection of transfectant clones have been already described (Iacovelli et al. 1996). Clones of FRTL-5 cells transfected with the empty vector pBJI were also produced to be used as control.
RT-PCR analysis of $L P A r$

RT-PCR was performed as previously described (Parruti et al. 1993). Five micrograms of FRTL-5 total RNA were reverse transcribed using random examers and PCR was performed for $30 \mathrm{~s}$ at $90{ }^{\circ} \mathrm{C}, 45 \mathrm{~s}$ at $60{ }^{\circ} \mathrm{C}$ and $1 \mathrm{~min}$ at $72{ }^{\circ} \mathrm{C}$ for 35 or 45 cycles, as indicated. The primers, derived from mouse sequences (Contos et al. 2000), were as follows: for the $1 p_{\mathrm{A} 1}$ CTAGCCACAGAATGGAACAC (forward primer) and TGCTCATTCGTGTATGGAGC (reverse primer); for the $1 \mathrm{p}_{\mathrm{A} 2}$ ATGGGCCAGTGCTAC TACAA (forward primer) and AACATGAGGAAGAG GTAGGC (reverse primer); for the $\mathrm{lp}_{\mathrm{A} 3}$ ATGAATGAG TGTCACTATGACAA (forward primer) and ACCGG GCCAGTGTTAAACAT (reverse primer). Rat testis total RNA was used as positive control.

\section{cAMP assay and inositol phosphate (IP) formation analysis}

The intracellular content of cAMP in transfected cells was determined by a method previously described (Iacovelli et al. 1996). Briefly, cells were seeded in 96-well plates at a density of $5 \times 10^{4}$ cells/well and grown to confluency, then starved of hormones and serum for $48 \mathrm{~h}$. Cells were washed twice with pre-warmed Hanks' balanced salt solution (HBSS) and added with HBSS containing $0.4 \%$ BSA, $10 \mathrm{mM}$ Hepes and $0.5 \mathrm{mM}$ 3-isobutyl-1methylxanthine. Incubations were continued at $37^{\circ} \mathrm{C}$ for $30 \mathrm{~min}$ with appropriate stimuli. The reaction was stopped by aspirating the incubation medium and adding ice-cold ethanol. The intracellular cAMP content was measured using a commercial RIA. The data shown are means \pm S.E.M. of three or four independent experiments each assayed in triplicate.

Total IP production was determined as described (Iacovelli et al. 1999). Briefly, cells plated for IP assay were overnight loaded with $\left[{ }^{3} \mathrm{H}\right] \mathrm{D}-$ myo-inositol $(5 \mu \mathrm{Ci} / \mathrm{ml})$ in M199 serum-free medium. Cells were washed twice with pre-warmed HBSS, incubated for $15 \mathrm{~min}$ at $37^{\circ} \mathrm{C}$ in HBSS buffer containing $10 \mathrm{mM}$ Hepes and $10 \mathrm{mM} \mathrm{LiCl}$, $\mathrm{pH} 7 \cdot 3$ and then stimulated with the indicated agonists for $30 \mathrm{~min}$. Total $\left[{ }^{3} \mathrm{H}\right] \mathrm{IP}$ was extracted with perchloric acid, neutralised and analysed by ion exchange chromatography on a Dowex column.

\section{Western blot for phosphorylated extracellular signal-regulated} kinases (ERK1/2)

The Western blot for phosphorylated ERK1/2 was performed as previously described with minor modifications (Brondello et al. 1997, Della Rocca et al. 1997). Briefly cells were grown to $50 \%$ confluency in six-well plates and starved of hormones and serum for $48 \mathrm{~h}$. Cells were stimulated in the same buffer as for cAMP assay at $37^{\circ} \mathrm{C}$ for $30 \mathrm{~min}$, then washed twice with ice-cold PBS and lysed in Triton X-100 lysis buffer for $15 \mathrm{~min}$ at $4{ }^{\circ} \mathrm{C}$. 

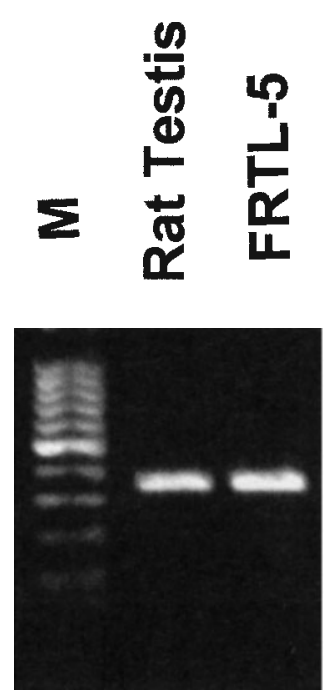

IpA1
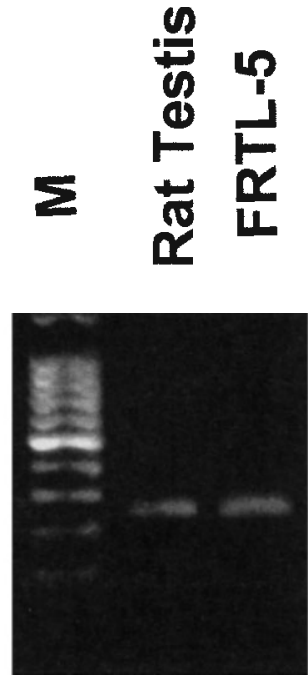

IpA2
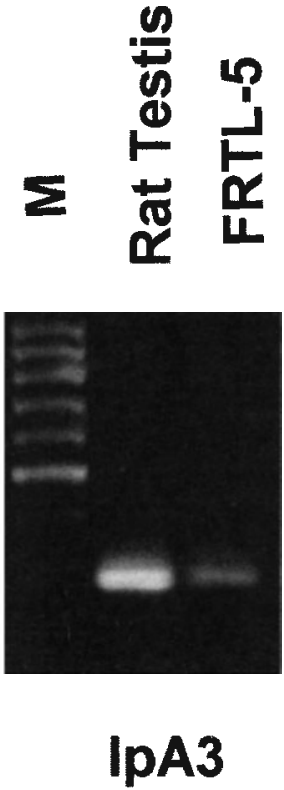

Figure 1 RT-PCR analysis of LPAr subtypes in FRTL- 5 cells. Five micrograms of FRTL-5 total RNA were reverse transcribed using random examers and PCR was performed for 45 cycles. Rat testis RNA was analysed in parallel as a positive control. Molecular mass markers (M) are shown.

Samples were clarified by centrifugation at $12000 \mathrm{~g}$ for 10 min at $4{ }^{\circ} \mathrm{C}$. Equal amounts of proteins from supernatants $(50 \mu \mathrm{g})$ were separated by SDS-PAGE $(12.5 \%$ acrylamide, $0 \cdot 0625 \%$ bisacrylamide). Proteins were transferred and probed using a commercial anti-phospho specific antibody against phosphorylated ERK1/2.

\section{Confocal analysis and immunofluorescence}

Confocal analysis was performed as previously described (Iacovelli et al. 2001). FRTL-5 cells were seeded on glass chamber slides. After agonist stimulation, cells were fixed

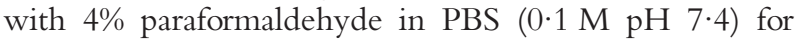
$15 \mathrm{~min}$ at room temperature. The autofluorescence was quenched by incubation for $30 \mathrm{~min}$ in $50 \mathrm{mM} \mathrm{NH}_{4} \mathrm{Cl}$, $50 \mathrm{mM}$ glycine in PBS and non-specific interactions were blocked by treatment with blocking solution $(0 \cdot 05 \%$ saponin, $0.5 \% \mathrm{BSA}$ in $\mathrm{PBS}$ ) for $30 \mathrm{~min}$ at room temperature. Cells were incubated overnight at $4{ }^{\circ} \mathrm{C}$ with antiarrestin monoclonal antibody $\mathrm{F} 4 \mathrm{C} 1$ (kindly provided by L A Donoso, Wills Eye Hospital, Philadelphia, PA, USA) in blocking solution. The chamber slides were then incubated with blocking solution containing Alexa-488 (Molecular Probes, Eugene, OR, USA) (1:400) antimouse IgGs for $1 \mathrm{~h}$ at room temperature. From the incubation with the secondary antibody, each incubation step was carried out in the dark and followed by careful washes with PBS (six times/3 min each). After immunostaining the coverslips were mounted on slides with
Mowiol 4-88, and analysed by the Confocal Imaging System Ultraview (Perkin Elmer, Cambridge, UK).

\section{${ }^{3}$ H]thymidine uptake}

This experiment was performed essentially as previously described (Iacovelli et al. 1996), with minor modifications. Briefly, cells were plated in 96-well plates $\left(10^{4}\right.$ cells/well) and allowed to grow for 4 days. After $48 \mathrm{~h}$ of starvation in Coon's modified F-12 medium plus $0.3 \%$ BSA and $20 \mathrm{mM}$ glutamine, the cells were stimulated as appropriate for $30 \mathrm{~h}$ and a pulse of $\left[{ }^{3} \mathrm{H}\right]$ thymidine was given in the last 6-8 h.

\section{Statistical analysis}

All the experiments are presented as the average of duplicate or triplicate determinations repeated at least three times. Statistical analysis was carried out by either Student's $t$-test or Dunnett ANOVA.

\section{Materials}

5-Bromo-4-chloro-3-indolyl phosphate and nitro blue tetrazolium were from Gibco BRL; forskolin (FSK) from Calbiochem (Darmstadt, Germany); glutamine, penicillin/ streptomycin and calf serum from Gibco; Tris, SDS, bromophenol blue and G418 from Fluka (Sigma-Aldrich); acrylamide and bisacrylamide from Promega; cAMP assay 
kit and $\left[{ }^{3} \mathrm{H}\right]$ thymidine from Amersham; alkaline phosphatase-conjugate goat anti-mouse IgG from Pierce (Rockford, IL, USA); anti-phospho ERK1/2 antibody from Promega. All the other materials were from Sigma (Milan, Italy).
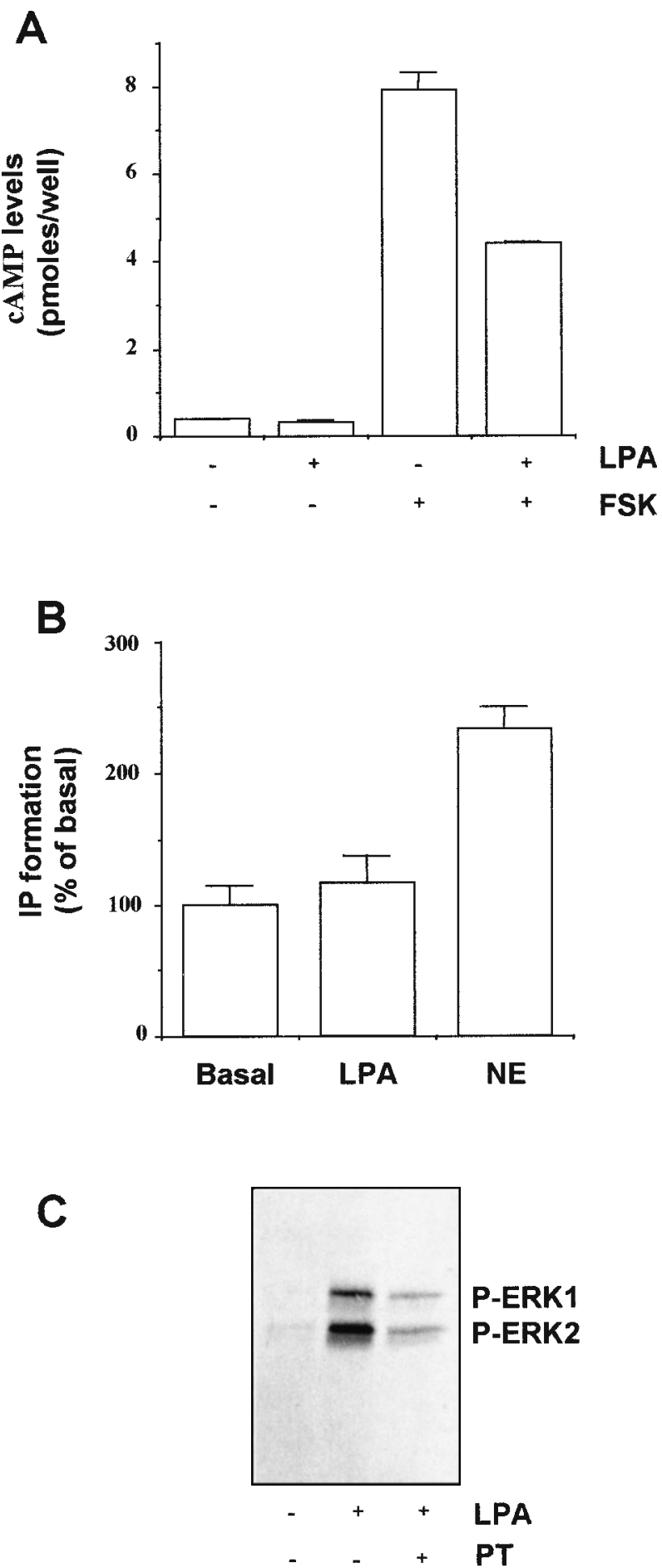

Journal of Endocrinology (2002) 174, 103-110

\section{Results and Discussion}

The presence of LPAr on the rat thyroid FRTL- 5 cells was suggested by previous evidence mostly based on pharmacological approaches (Okajima et al. 1997, Falasca et al. 1998). More recently, three LPAr subtypes have been identified by molecular cloning making the human and mouse sequences available (Contos et al. 2000, Pierce et al. 2001). We used RT-PCR to document the expression of LPAr in FRTL-5 cells and to identify the LPAr subtypes (Contos et al. 2000) which are expressed on these cells. Rat testis, in which the three LPAr subtypes are expressed, was used as a positive control. RT-PCR analysis of the FRTL-5 RNA showed one band of the expected size for each of the LPAr subtypes considered, indicating that FRTL-5 express $1 p_{\mathrm{A} 1}, \mathrm{lp}_{\mathrm{A} 2}$ and $1 \mathrm{p}_{\mathrm{A} 3}$ receptors (Fig. 1). Based on these experiments, the $\operatorname{lp}_{\mathrm{A} 3}$ appeared to be less abundant, as compared with the testis.

Since LPAr can couple to different heterotrimeric G-proteins for signalling, and the signalling pathways are cell-type dependent (Bandoh et al. 1999, Young et al. 1999, Contos et al. 2000, Hernandez et al. 2000, Pierce et al. 2001), in initial experiments we characterised the LPA-mediated signalling in FRTL-5 cells. Exposure of FRTL-5 cells to LPA reduced FSK-stimulated intracellular cAMP accumulation in a dose-dependent manner $\left(\mathrm{IC}_{50}=10 \mu \mathrm{M}\right)$. Maximal reduction of FSK-stimulated cAMP levels was observed at doses between 20 and $70 \mu \mathrm{M}$. At $20 \mu \mathrm{M}$ LPA, FSK-stimulated cAMP was decreased by $45-50 \%$ (Fig. 2A). At this concentration LPA alone did not stimulate cAMP production in FRTL-5 cells. In these cells, the stimulation of LPAr activated MAP kinases and this effect was likely mediated by a pertussis toxin (PT)-sensitive G-protein, since the pretreatment with PT totally prevented the phosphorylation and hence the activation of ERK1/2 (Fig. 2C). The possible coupling to $\mathrm{Gq}$ was assessed by measuring total IP production after LPA exposure. We found that exposure to LPA (up to $50 \mu \mathrm{M}$ ) did not induce any detected IP accumulation, while in parallel experiments the activation of the $\alpha 1$ adrenergic receptors by $1 \mu \mathrm{M}$ norepinephrine (NE) increased IP production by $2-$ to 3 -fold (Fig. 2B). Taken together this set of experiments indicates that in FRTL-5 cells the LPAr are mainly coupled to a PT-sensitive

Figure 2 Lysophosphatidic acid (LPA)-stimulated signalling in FRTL-5. (A) FRTL-5 cells were stimulated for 30 min with $20 \mu \mathrm{M}$ LPA or with $10 \mu \mathrm{M}$ forskolin (FSK) or both and cAMP was measured. Data are the means \pm S.E.M. of three separate experiments performed in triplicate. (B) FRTL-5 cells were stimulated for 30 min with $50 \mu \mathrm{M}$ LPA or $1 \mu \mathrm{M}$ norepinephrine (NE) and the inositol phosphate (IP) formation was measured. Data are the means \pm S.E.M. of three separate experiments performed in duplicate. (C) Immunoblot representing phospho-ERK1/2 in L5pBJI untreated or treated with $20 \mu \mathrm{M} \mathrm{LPA}$ and $1 \mathrm{nM}$ pertussis toxin (PT) (which was preincubated for $16 \mathrm{~h}$ ). The experiment is representative of two similar. 

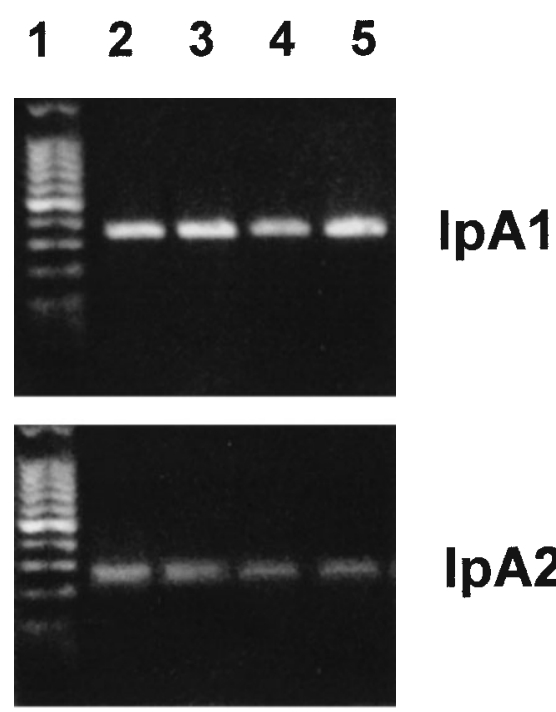

IpA2

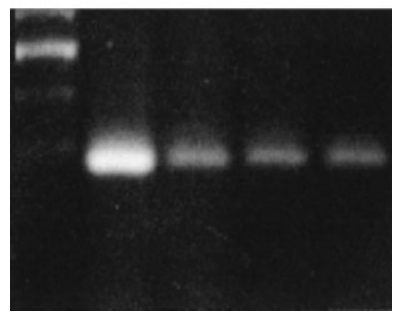

\section{IpA3}

Figure 3 RT-PCR analysis of LPAr subtypes in L5pBJI, L5 3 arr 1 and L5GRK2. Five micrograms of total RNA were reverse transcribed using random examers and PCR was performed for 35 cycles (exponential phase of the reaction). Lanes are: 1: molecular mass markers, 2: rat testis, 3: L5pBJI; 4: L5ßarr1; 5: L5GRK2.

G-protein. We hypothesise that the stimulation of LPAr induces the dissociation of the PT-sensitive G-protein heterotrimer and the release of free $\mathrm{G} \alpha$ inhibits adenylyl cyclase activity and reduces intracellular cAMP levels, while the MAP kinase cascade could be stimulated by free $G \beta \gamma$.

The main goal of this study was to investigate whether the LPAr are regulated by the GRK/arrestin-dependent mechanism for homologous desensitisation. In order to investigate whether GRKs and arrestins are involved in the regulation of LPAr-mediated signalling, we used the FRTL-5 cell line permanently transfected to overexpress GRK2 (named L5GRK2 cells) or $\beta$-arrestin1 (L5 $\beta$ arr1 cells). We transfected GRK2 and $\beta$-arrestin1 since these subtypes are expressed in FRTL-5 cells and, as documented by our previous studies, represent the physiologically relevant subtypes in these cells (Iacovelli et al. 1996, 1999). FRTL-5 cells transfected with the empty vector (L5pBJI cells) were used as control cells in this study. All the cell clones were used for limited cell passages (15-20 passages), in order to avoid changes in cellular responses due to ageing. In all experiments the L5pBJI,

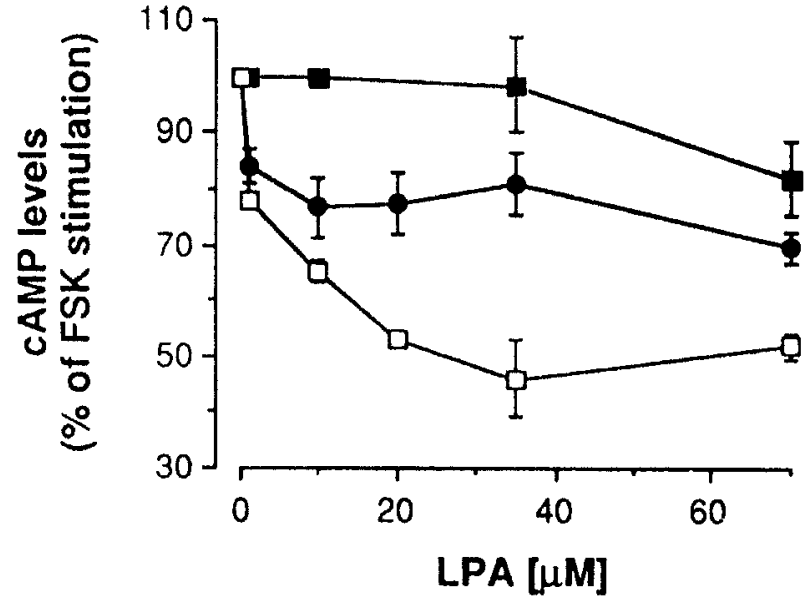

Figure 4 Regulation of LPAr signalling by $\beta$-arrestin 1 and GRK2. L5pBJI ( $\square$ ), L5ßarr1 (ם) and L5GRK2 (-) were stimulated for 30 min with $10 \mu \mathrm{M}$ FSK plus the indicated concentrations of LPA and cAMP accumulation was measured. Data are the means \pm S.E.M. of three separate experiments performed in triplicate. All the values in L5ßarr1B were statistically significant vs L5pBJI at $P<0 \cdot 01$, except for LPA 1,40 and $70 \mu \mathrm{M}$ in L5GRK2 which were significant at $P<0 \cdot 05$.

L5 $\beta$ arr 1 and L5GRK2 cells were age-matched. These cell lines represent a useful experimental model for investigating the regulation of GPCR signalling, as described in previous studies. We selected FR TL-5 clones in which the level of GRK2 or $\beta$-arrestin1 overexpression did not exceed 3- to 4-fold that of the endogenous proteins, since the moderate overexpression of GRK2 and $\beta$-arrestin1 resulted in a selective regulation of different GPCRs endogenously expressed in FRTL-5 cells (Iacovelli et al. 1999). For example we could demonstrate that TSH receptors, which in these cells mediate fundamental responses such as proliferation and differentiation, are strictly controlled by GRK/ $\beta$-arrestin regulatory mechanisms, while the $\alpha 1$-adrenergic receptors were unaffected by GRK2 overexpression (Iacovelli et al. 1999).

The expression of the three LPAr subtypes was determined in L5pBJI, L5ßarr1 and L5GRK2 by RT-PCR. The PCR was performed for 35 cycles, when the reaction is at the exponential phase (not shown). The expression of the $1 p_{\mathrm{A} 1}, \mathrm{lp}_{\mathrm{A} 2}$ and $\mathrm{lp}_{\mathrm{A} 3}$ was similar in all the FRTL-5 clones analysed, indicating that the overexpression of $\beta$-arrestin1 and GRK2 did not alter the levels of LPAr (Fig. 3). The ability of LPA to inhibit FSK-stimulated cAMP accumulation was blunted in L5GRK2 and more markedly in L5ßarr1. LPA $(35 \mu \mathrm{M})$ decreased FSKstimulated intracellular cAMP by $46 \cdot 2 \pm 7 \%$ in L5pBJI and only by $19 \cdot 2 \pm 6 \% \quad(P<0 \cdot 01 \quad$ vs control $)$ and $3 \cdot 3 \pm 8 \cdot 7 \% \quad(P<0 \cdot 01$ vs control $)$ in L5GRK2 and in L5 $\beta$ arr1 respectively (Fig. 4). This indicates that the LPA-stimulated signalling is desensitised by GRK2 and $\beta$-arrestin1 overexpression. Consistently, the MAP kinase 

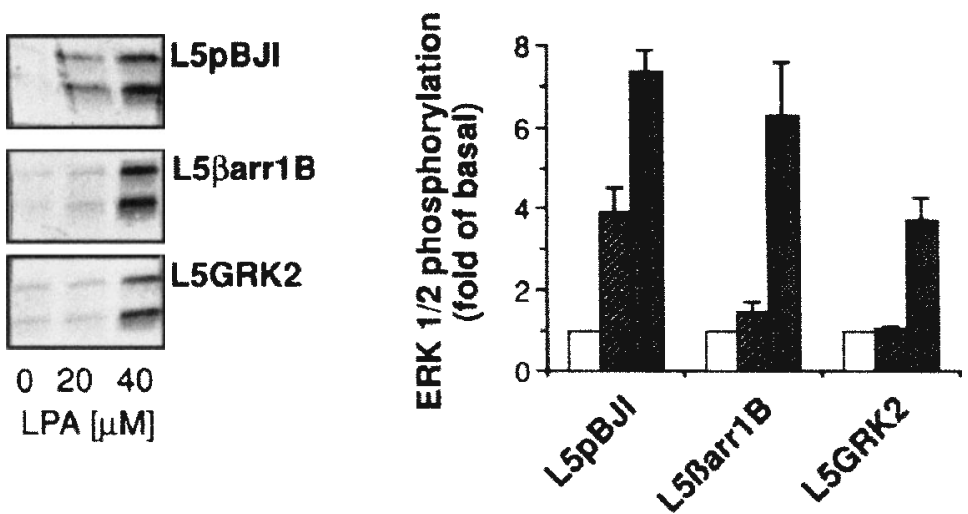

Figure 5 Regulation of LPAr-stimulated ERK1/2 phosphorylation by $\beta$-arrestin 1 and GRK2. On the left: representative immunoblot showing phospho-ERK1/2 in L5pBJI, L5ßarr1 and L5GRK2 after exposure to the indicated concentrations of LPA. On the right: the quantitative analysis of three separate immunoblots of cells untreated (first bars in each group) or treated with $20 \mu \mathrm{M}$ (second bars) or $40 \mu \mathrm{M}$ (third bars) LPA. Data are expressed as fold of basal of ERK1/2 phosphorylation in which ERK1/2 phosphorylation in L5pBJI was defined as 1 . Values represent means \pm S.E.M. Statistically significant differences vs L5pBJI were observed at $20 \mu \mathrm{M} \mathrm{LPA}$ in L5 $\beta$ arr 1 and in L5GRK2 $(P<0 \cdot 01)$ and at $40 \mu \mathrm{M} \mathrm{LPA}$ in L5GRK2 $(P<0 \cdot 05)$.

activation, which is the other signalling cascade activated by the LPAr (presumably through G $\beta \gamma$ ) was blunted in L5 GRK2 and in L5ßarr1 cells. Exposure to $20 \mu \mathrm{M}$ LPA increased the phosphorylation of ERK1/2 by $\sim 3$-fold in L5pBJI while it induced a modest increase in L5 $\beta$ arr1 $(P<0 \cdot 01$ vs control) and was ineffective in L5 GRK2 $(P<0 \cdot 01$ vs control). At $40 \mu \mathrm{M}$ LPA, ERK1/2 phosphorylation was increased by $\sim 6$-fold in L5pBJI and by $\sim 5$-fold and $\sim 2 \cdot 5$-fold in L5 $\beta$ arr1 (difference from control not statistically significant) and L5GRK2 $(P<0.05$ vs control) respectively (Fig. 5).

The mechanism of GPCR regulation by $\beta$-arrestin has been, at least in part, elucidated (Miller \& Lefkowitz 2001). It has been shown for many GPCRs that agonist stimulation induces the translocation of $\beta$-arrestin to plasma membranes, where it binds to the phosphorylated receptor and prevents the interaction between the receptor and the G-protein. This step is usually followed by the internalisation of the receptor and $\beta$-arrestin in intracellular vesicles. We used a confocal microscopy analysis to assess whether the exposure to LPA promotes the redistribution of $\beta$-arrestin in FRTL-5 cells (Fig. 6). Under basal conditions $\beta$-arrestin was diffused in the cytosol of FRTL-5 cells. LPA treatment $(35 \mu \mathrm{M})$ induced a rapid $(2 \mathrm{~min})$ translocation of $\beta$-arrestin to plasma membranes which was followed (at 10 min treatment) by the internalisation of $\beta$-arrestin in intracellular vesicles. Similar results were obtained with L5 $\beta$ arr1 (Fig. 6) and with L5pBJI (not shown) cells. These findings document that in FRTL-5 $\beta$-arrestin is redistributed in an LPAdependent manner and suggest that the LPAr are regulated by $\beta$-arrestin by a mechanism similar to that documented for the majority of GPCRs.
Previous studies documented that LPA stimulates FRTL-5 cell proliferation (Falasca et al. 1998) and we measured $\left[{ }^{3} \mathrm{H}\right]$ thymidine uptake in L5ßarr1 and in L5 GRK2 cells to test whether GRK2 and $\beta$-arrestin1 could have a role in the regulation of LPAr-mediated cell proliferation. The mitogenic response induced by $35 \mu \mathrm{M}$ LPA was substantially blunted in L5 $\beta$ arr1 and in L5GRK2 cells as compared with L5pBJI. $\left[{ }^{3} \mathrm{H}\right]$ thymidine uptake was inhibited by $69 \pm 6 \%$ in L5 $\beta$ arr1 and $69 \cdot 8 \pm 4 \cdot 5 \%$ in L5GRK2 cells as compared with L5 pBJI cells (Fig. 7). This finding demonstrates that the regulation of LPAr by GRK2 and $\beta$-arrestin1 is functionally relevant. The observation that the overexpression of GRK2 and $\beta$-arrestin1 reduced both TSH-stimulated (Iacovelli et al. 1996) and LPA-stimulated (present work) $\left[{ }^{3} \mathrm{H}\right]$ thymidine uptake in FRTL-5 further supports our previous hypothesis that GRK2 and $\beta$-arrestin1 act as negative regulators of GPCR-stimulated proliferative responses in thyroid cells.

In summary, we have shown that FRTL-5 thyroid cells express three subtypes of LPAr which are functionally coupled to a PT-sensitive G-protein. Agonist-stimulated receptor activation inhibited the adenylyl cyclase and stimulated ERK1/2 phosphorylation. This pathway is involved in the proliferative response stimulated by LPA, as indicated by the analysis of $\left[{ }^{3} \mathrm{H}\right]$ thymidine uptake. All these responses elicited by LPA were substantially blunted in cells transfected to overexpress GRK2 and $\beta$-arrestin1, indicating that, similar to many other GPCRs, the LPAr is desensitised by a GRK2/ $\beta$-arrestin1-mediated mechanism. It should also be noted that the moderate levels of GRK2 and $\beta$-arrestin1 overexpression achieved by transfection in FR TL5 cells are similar to those obtained in cells after different treatments (Iacovelli et al. 1999). This 


\section{$\beta$-arrestin}

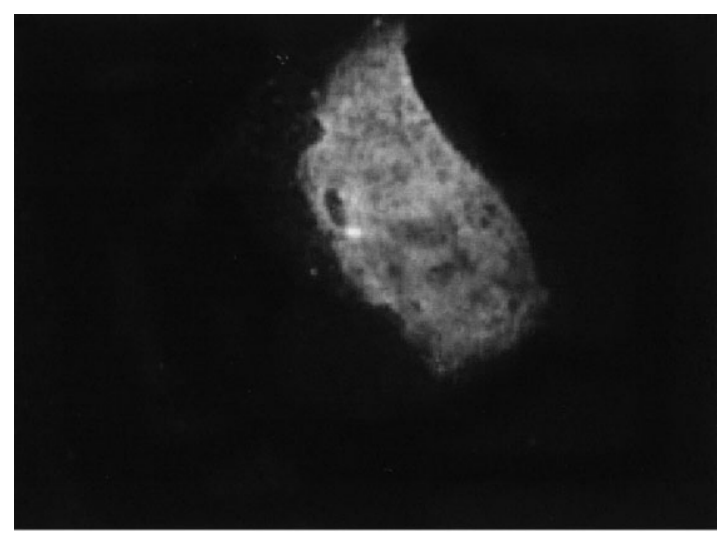

Basal

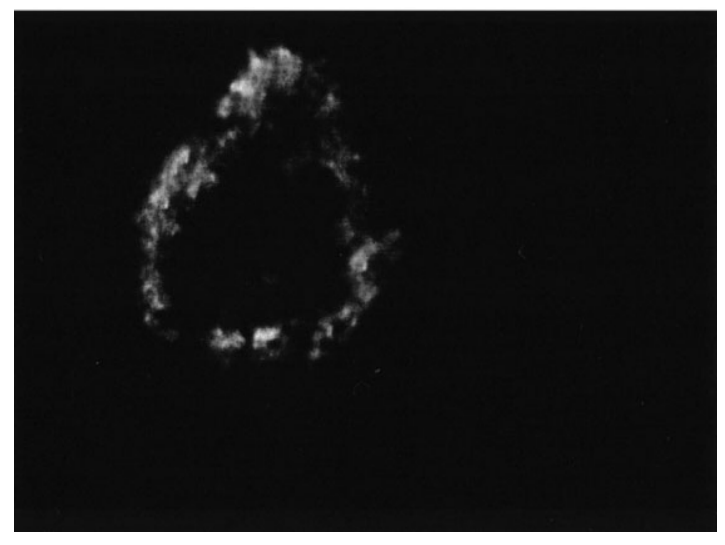

\section{LPA 2 min}

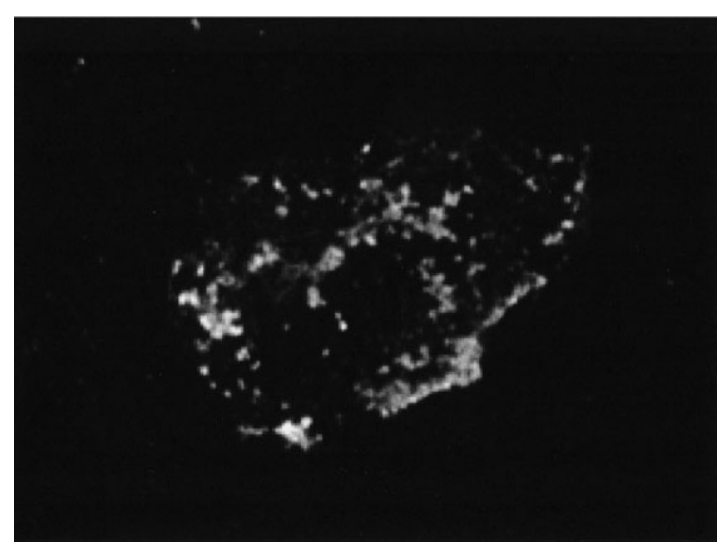

\section{LPA $10 \mathrm{~min}$}

Figure 6 Translocation of $\beta$-arrestin by LPA in FRTL-5. The fluorescence imaging of $\beta$-arrestin using confocal microscopy is shown. L5 3 arr 1 cells were untreated (Basal) or treated with LPA $(35 \mu \mathrm{M})$ for the indicated times. The experiment shown was repeated four times with similar results.

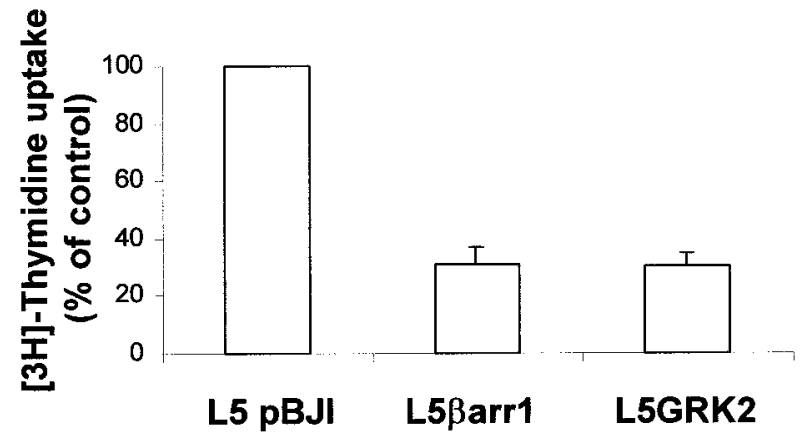

Figure 7 LPA-induced DNA synthesis is blunted in FRTL5 cells overexpressing $\beta$-arrestin 1 and GRK2. Quiescent L5 $\beta$ arr 1 and L5GRK2 cells were stimulated with $35 \mu \mathrm{M}$ LPA and $\left[{ }^{3} \mathrm{H}\right]$ thymidine uptake was measured. Data are means \pm S.E.M. of four separate experiments each performed in triplicate. The $\left[{ }^{3} \mathrm{H}\right]$ thymidine uptake reduction in L5 $\beta$ arr1 and L5GRK2 vs L5 pBJI cells was statistically significant $(P<0 \cdot 01)$.

indicates that such levels can be reached in cells that naturally express these regulatory proteins and that the modulation of the levels of GRK2/ $\beta$-arrestin1 represents one factor that could play a role in controlling the LPAr-mediated effects, including the stimulation of proliferative responses in thyroid cells. In this regard it should be emphasised that a recent study has documented the overexpression of the high-affinity receptor edg-4 ( $\left(\mathrm{p}_{\mathrm{A} 2}\right)$ in differentiated thyroid cancer (Schulte et al. 2001). A knowledge of the mechanisms that regulate receptormediated proliferative responses in thyroid cells may provide a novel therapeutic target to control pathological cell proliferation.

\section{Acknowledgements}

This work was supported by the Associazione Italiana per la Ricerca sul Cancro (AIRC), and by a Consiglio Nazionale delle Ricerche (CNR) Target Project in Biotechnology.

\section{References}

Bandoh K, Aoki J, Hosono H, Kobayashi S, Kobayashi T, Murakami-Murofushi K, Tsujimoto M, Arai H \& Inoue K 1999 Molecular cloning and characterization of a novel human G-protein-coupled receptor, EDG7, for lysophosphatidic acid. Journal of Biological Chemistry 274 27776-27785.

Brondello JM, Brunet A, Pouyssegur J \& McKenzie FR 1997 The dual specificity mitogen-activated protein kinase phosphatase-1 and -2 are induced by the p42/p44 MAPK cascade. Journal of Biological Chemistry 10 1368-1376.

Contos JJ, Ishii I \& Chun J 2000 Lysophosphatidic acid receptors. Molecular Pharmacology 58 1188-1196.

Della Rocca GJ, van Biesen T, Daaka Y, Luttrell DK, Luttrell LM \& Lefkowitz RJ 1997 Ras-dependent mitogen-activated protein kinase activation by $\mathrm{G}$ protein-coupled receptors. Convergence of Gi- and Gq-mediated pathways on calcium/calmodulin, Pyk2, and Src kinase. Journal of Biological Chemistry 272 19125-19132. 
Falasca M, Iurisci C, Carvelli A, Sacchetti A \& Corda D 1998 Release of the mitogen lysophosphatidylinositol from H-Ras-transformed fibroblasts; a possible mechanism of autocrine control of cell proliferation. Oncogene 16 2357-2365.

Fischer DJ, Liliom K, Guo Z, Nusser N, Virag T, MurakamiMurofushi K, Kobayashi S, Erickson JR, Sun G, Miller DD \& Tigyi G 1998 Naturally occurring analogs of lysophosphatidic acid elicit different cellular responses through selective activation of multiple receptor subtypes. Molecular Pharmacology 54 979-988.

Gueguen G, Gaige B, Grevy JM, Rogalle P, Bellan J, Wilson M, Klaebe A, Pont F, Simon MF \& Chap H 1999 Structure-activity analysis of the effects of lysophosphatidic acid on platelet aggregation. Biochemistry 29 8440-8450.

Hernandez M, Barrero MJ, Crespo MS \& Nieto ML 2000 Lysophosphatidic acid inhibits $\mathrm{Ca}^{2+}$ signaling in response to epidermal growth factor receptor stimulation in human astrocytoma cells by a mechanism involving phospholipase $\mathrm{C}$ (gamma) and a G(alpha) protein. Journal of Neurochemistry 75 1575-1582.

Iacovelli L, Franchetti R, Masini M \& De Blasi A 1996 GRK2 and beta-arrestin 1 as negative regulators of thyrotropin receptorstimulated response. Molecular Endocrinology 10 1138-1146.

Iacovelli L, Franchetti R, Grisolia D \& De Blasi A 1999 Selective regulation of $G$ protein-coupled receptor-mediated signaling by G protein-coupled receptor kinase 2 in FRTL-5 cells: analysis of thyrotropin, alpha(1B)-adrenergic, and $\mathrm{A}(1)$ adenosine receptor-mediated responses. Molecular Pharmacology 56 316-324.

Iacovelli L, Capobianco L, Salvatore L, Sallese M, D'Ancona GM \& De Blasi A 2001 Thyrotropin activates mitogen-activated protein kinase pathway in FRTL- 5 by a cAMP-dependent protein kinase A-independent mechanism. Molecular Pharmacology 60 924-933.

Kakizawa K, Nomura H, Yoshida A \& Ueda H 1998 Signaling of lysophosphatidic acid-evoked chloride current: calcium release from inositol trisphosphate-sensitive store. Brain Research. Molecular Brain Research 30 232-237.
Kraneburg O \& Moolenar WH 2001 Ras-MAP kinase signaling by lysophosphatidic acid and other $\mathrm{G}$ protein-coupled receptor agonists. Oncogene 26 1540-1546.

Miller WE \& Lefkowitz RJ 2001 Expanding roles for beta-arrestins as scaffolds and adapters in GPCR signaling and trafficking. Current Opinion in Cell Biology 13 139-145.

Okajima F, Tomura H, Sho K, Kimura T, Sato K, Im DS, Akbar M \& Kondo Y 1997 Sphingosine 1-phosphate stimulates hydrogen peroxide generation through activation of phospholipase $\mathrm{C}-\mathrm{Ca}^{2+}$ system in FRTL-5 thyroid cells: possible involvement of guanosine triphosphate-binding proteins in the lipid signaling. Endocrinology 138 220-229.

Parruti G, Peracchia F, Sallese M, Ambrosini G, Masini M, Rotilio D \& De Blasi A 1993 Molecular analysis of human $\beta$ arrestin-1: cloning, tissue distribution, and regulation of expression. Journal of Biological Chemistry 268 9753-9761.

Pierce KL, Luttrell LM \& Lefkowitz RJ 2001 New mechanisms in heptahelical receptor signaling to mitogen activated protein kinase cascades. Oncogene 26 1532-1539.

Schulte KM, Beyer A, Kohrer K, Oberhauser S \& Roher HD 2001 Lysophosphatidic acid, a novel lipid growth factor for human thyroid cells: over-expression of the high-affinity receptor edg4 in differentiated thyroid cancer. International Journal of Cancer $\mathbf{1 5}$ 249-256.

Young KW, Challiss RA, Nahorski SR \& MacKrill JJ 1999 Lysophosphatidic acid-mediated $\mathrm{Ca}^{2+}$ mobilization in human SH-SY5Y neuroblastoma cells is independent of phosphoinositide signalling, but dependent on sphingosine kinase activation. Biochemistry Journal 343 45-52.

Received in final form 18 February 2002

Accepted 4 April 2002 